\title{
Optimal Tilts*
}

\author{
Malcolm Baker \\ Harvard Business School, Acadian Asset Management, and NBER \\ Terry Burnham \\ Chapman University \\ Ryan Taliaferro \\ Acadian Asset Management
}

February 12, 2016

\begin{abstract}
We examine the optimal weighting of four characteristic tilts in US equity markets over the period from 1968 through 2014. We define a "tilt" as a positive-Sharpe-ratio, characteristicbased portfolio strategy that requires relatively low annual turnover and a "trade" as a characteristic-based portfolio strategy that requires relatively high annual turnover and liquidity demands. Size is a tilt, because of its very low turnover; high frequency reversal is a trade. This dichotomy is necessary to make practical use of Fama-French style factor regressions. Unlike low-turnover tilts, a full history of transaction costs and an estimate of capacity is critical to determine the expected return, and hence the optimal allocation and explanatory power of trades. The mean-variance optimal tilts toward value (20\%), size (26\%), and profitability (23\%) are roughly equal to each other and to the optimal low beta tilt (24\%). The remaining $7 \%$ is allocated to bond market factors. Notably, in an apples-to-apples comparison, the low beta tilt is not subsumed by other tilts. Rather, it is the second highest of the four.
\end{abstract}

*The views expressed herein are those of the authors and do not necessarily reflect the views of the National Bureau of Economic Research, Harvard Business School, Chapman University, or Acadian Asset Management. The views should not be considered investment advice and do not constitute or form part of any offer to issue or sell, or any solicitation of any offer to subscribe or to purchase, shares, units, or other interests in any particular investments. 


\section{Introduction}

Systematic equity investing goes by many different names: rules-based investing, sorts, style, characteristic-based portfolios, factor investing, smart beta, alternative beta, and even genius beta. ${ }^{1}$ Investors use characteristic-based portfolios in two ways. The first is to evaluate risk. Across multiple equity managers, an investor may monitor and manage intentional or unintentional exposures to one or more characteristics. The second is to generate return, by combining characteristics in a single portfolio, or by assembling multiple, single-characteristic portfolios.

We can draw another distinction among these investment strategies. Some are persistent “tilts.” For example, small capitalization investing requires little annual trading, because small stocks this year are likely to have been small stocks last year. And other strategies are higher frequency “trades.” High frequency reversal, or even momentum and growth investing, involves much more frequent rebalancing. These strategies often also involve more illiquid stocks, and require a careful eye on implementation costs.

When is this categorization of systematic strategies important? It is not crucial for the evaluation of risk. Both tilts and trades can be used to assess contributions to portfolio risk. But the distinction is critical to portfolio construction. Forming mean-variance efficient portfolios, or assessing the incremental value of adding one characteristic portfolio to an existing set, requires that the portfolios under consideration be equally implementable. For example, suppose the risk and gross return properties of a low risk portfolio could be roughly matched with a blend of a momentum portfolio and a high frequency reversal portfolio. The returns net of implementation costs, and therefore the capacity, of the low risk portfolio are much greater, so the comparison of

\footnotetext{
${ }^{1}$ The consulting firm Segal Rogerscasey asks, “Genius Beta: Why Settle for Just Smart Beta,” in its Investment Focus of June 2015.
} 
gross returns is unhelpful. While the gross returns of tilts can be reasonably compared on an apples-to-apples basis, the gross returns of trades cannot. A more ambitious model, complete with a long history of transaction cost estimates, assets under management, and cash flows, is needed to arrive at a mean-variance optimal combination of single-characteristic portfolios. In this paper we focus more narrowly on the optimal combination of tilts, which are most relevant for large-scale equity investors like pension funds, endowments, and sovereign wealth funds.

We find that over the period 1968 through 2014, the ideal balance of risk and return would have been achieved by tilts toward value of $20 \%$, size of $26 \%$, and profitability of $23 \%$. These three tilts are roughly equal to each other, and to the optimal low beta tilt of $24 \%$. The remaining $7 \%$ is allocated to bond market factors. Notably, in an apples-to-apples comparison, the low beta tilt is not subsumed by other tilts. Rather, it is the second highest of the four.

\section{The Implementation of Characteristic Portfolios}

We start by choosing a standard set of characteristic portfolios, including one that is long lower risk stocks and short higher risk stocks. In this section, we describe the selection process, the measurement of risk, and—crucially—-the relative ability to implement these portfolios. The output is four portfolios that we describe as tilts. These are implemented at modest rates of turnover. We distinguish these four from three other portfolios that have much lower capacity because of their inherent higher turnover. Finally, to this set, we add two easily implementable tilts from the fixed income market: one that captures duration, and the other that captures credit risk. 


\section{A. Choosing Characteristics}

The literature on capital market anomalies offers a wide array of firm characteristics to use in the prediction of stock returns. An anomaly is conventionally defined as a deviation from the return predicted by the Capital Asset Pricing Model (CAPM). The CAPM is of course an imperfect theoretical model of stock returns, so these deviations can be interpreted either as missing risk factors or mispricings. These fall into several categories: Small, safe, value, conservative growth, and profitability. Technical indicators, momentum and reversal—which rely only on past returns_-round out a preliminary list.

Safe stocks, defined as low beta or low volatility, have relatively high returns in Jensen, Black, and Scholes (1972) and more recently in Baker, Bradley, and Wurgler (2011) and Frazzini and Pedersen (2014). Small stocks, defined as relatively low market capitalization, have higher-than-CAPM predicted returns in Banz (1981). Value stocks, defined as those with relatively low price/book have abnormally high returns in Rosenberg, Reid, and Lanstein (1985), Chan, Hamao, and Lakonishok (1991), and Fama and French (1992).

Returns after stock sales, IPOs, and SEOs are abnormally low, while returns after stock repurchases are abnormally high in Ritter (1991), Loughran and Ritter (1995), Pontiff and Woodgate (2006), and Daniel and Titman (2006). Relatedly, firms with high accruals (Sloan, 1996), relatively high capital expenditures (Titman, Wei, and Xie, 2004; Xing, 2008), large growth in net operating assets (Hirshleifer, Hou, Teoh, and Zhang, 2004) or total assets (Cooper, Gulen, and Schill, 2008) also have abnormally low returns. We refer to these patterns collectively as conservative or low growth.

Profitable firms have higher average stock returns in Basu (1983), Haugen and Baker (1996), Cohen, Gompers, and Vuolteenaho (2002), Fama and French (2006), and Novy-Marx 
(2013). Stock market returns exhibit momentum, in that firms with relatively high trailing returns have abnormally high average returns, and reversal over shorter horizons of a month or less in Jegadeesh (1990) and Jegadeesh and Titman (1993, 1995a, 1995b).

All of these return predictors can be measured back to the beginning of the stock return history to the early 1960s, and in many cases all the way back to the 1920s. The list that includes predictors with shorter histories is even longer, and is built on data on mutual fund and institutional holdings, governance, short selling, options, analyst recommendations and estimates, earnings announcement surprise, and more.

The goal of this paper is not to survey the vast array of capital market anomalies, but to analyze a simple and transparent subset that subsumes the themes in the long-history data. For that reason, we narrow our attention to an initial subset that includes the five factors in Fama and French (2015), as well as a simple implementation of momentum and one-month reversal from Jegadeesh and Titman (1993). To this list, we add risk, measured with a trailing estimate of beta. The initial set of tilts and trades is listed in Table I, where the simple factor definitions are shown. It would be straightforward to extend the analysis to a larger list of factors, but this would require reducing the length of the time series for factors with limited history, and likely an additional aggregation exercise designed to narrow the larger set of characteristics to a smaller number of principal components, along the lines of Stambaugh, Yu, and Yuan (2012).

\section{B. Measuring Risk}

We choose among three different measures of beta by selecting the best predictor of realized risk. On the assumption that beta is mispriced, a better predictor of beta should produce a larger anomaly. The first measure of beta uses the traditional five years of monthly returns; the 
second uses five years of three-day overlapping returns; and the third uses the correlation estimate from the second method plus a one-year daily volatility, as in Frazzini and Pedersen (2014). All are effective at spreading risk, as shown in Table II. The differences in realized beta between the top and bottom quintile portfolio, measured monthly and equally weighted, are 0.86 , 1.03 , and 1.05, respectively. We use the third approach, though the second and third produce nearly identical results.

The key is using three-day returns to estimate correlations. This has the effect of lowering the average betas of small stocks, which are individually less likely to trade in synch with the market overall, because of lower levels of liquidity. As a result, the improved measures of beta are lower for smaller capitalization stocks. As a practical matter, this makes the quintile spread portfolios in Table II somewhat harder to implement; but as we show in Section II.D below, it puts the beta tilt on par with the other characteristic tilts, like value and high profits, which have as much or more dispersion in smaller capitalization stocks as the three-day overlapping returns estimate of beta delivers.

As a side note, the spread in beta appears to come from both the selection across industries and the within-industry selection of stocks, as shown in the last two rows of Table II. The selection of stocks within an industry spreads risk from the highest to the lowest quintile by 0.82 , which is slightly more than the selection of industries, without reference to stock level information, which spreads risk by 0.66 .

\section{Forming Characteristic Portfolios}

We settle on seven characteristics in Table I: Low Beta, Value (Fama-French HML), Small Size (SMB), High Profits (RMW), Low Growth (CMA), Momentum (MOM), and 
Reversal (STREV). We compute portfolio returns for each following the approach pioneered by Fama and French (1993), forming factor portfolios with some consideration implicitly given to implementation costs. We discuss the effects of implementation in the next section. For example, the Fama-French value factor consists of dividing the universe into six portfolios according to NYSE breakpoints: small and big value, small and big neutral, and small and big growth. At the end of each June, six portfolios are rebalanced with market capitalization weights within each one. The value factor portfolio is long equal amounts of the two value portfolios and short equal amounts of the two growth portfolios. The NYSE breakpoints and value-weighting portfolios give the factor portfolio greater realism by giving less weight to tiny stocks.

Table III shows the performance of the seven factor portfolios over the period from 1968 through 2014. (The size factor is designed by Fama and French to be neutral to value.) All come directly from Ken French's data library except for the beta portfolio, which follows the FamaFrench conventions and end-of-June rebalances, and which uses the estimate of beta shown in the third row of Table I. The first three columns show the average annualized monthly return, the annualized standard deviation, and the Sharpe ratio, which is the ratio of the average to the standard deviation. These annualized returns range from $1.8 \%$ for Low Beta to $7.9 \%$ for Momentum.

The next four columns show the market-neutral performance of the seven factor portfolios. These are the results of a regression of each factor portfolio on the excess return on the value-weighted market portfolio (Fama-French MKT). The average market-neutral monthly return, or alpha, is equal to the annualized intercept. The standard deviation is equal to the annualized standard deviation of the regression residuals. And, the Sharpe ratio is again the average divided by the standard deviation. For example, the low beta factor portfolio by 
construction has a very low beta, and so on a market-neutral basis, its performance is much stronger, with a market-neutral annualized return of $6.4 \%$ and a market-neutral Sharpe ratio of 0.62 versus raw values of $1.8 \%$ and 0.11 . The average market return over Treasury bills was $5.6 \%$ over this period, so low betas enhance market-neutral performance. The performance of value, high profits, low growth, and momentum also improve with negative market exposure, but to a much smaller extent. Meanwhile, the size and reversal factor portfolios have somewhat weaker performance on a market-neutral basis because on average they have positive market exposure. The market-neutral annualized returns range from 1.3\% for Small Size to $8.6 \%$ for Momentum.

One important note: it is critical to form all of the characteristic portfolios the same way. For example, it is unreasonable to judge the returns on a long-only, large capitalization, low beta portfolio against the Fama-French-style long-short implementation of profits (CMA), with equal weights on small and large capitalization stocks. This is why we form the low beta characteristic portfolio using precisely the Fama-French methodology. It is long-short, and it blends beta tilts among both small and large stocks.

Mixing and matching can produce illogical conclusions. For example, using the identical measure of value but focusing on small stocks produces a portfolio that has a statistically positive alpha in Fama-French time series regressions. Using the identical measure of value but focusing on large stocks produces a portfolio that has a statistically negative alpha in FamaFrench time series regressions. We show this in Table IV. Similarly, long-short implementations in small stocks produce higher alphas than long-only implementations. All of these conclusions are silly. Controlling for value, value portfolios should not show positive or negative alphas, but because anomalies are generally stronger in small stocks, differences in portfolio construction, 
turnover, and liquidity can lead to more insidious conclusions that are as incorrect as this obviously spurious one, but harder to spot.

D. Implementation: Tilts versus Trades

Six of the seven, market-neutral factor portfolios have Sharpe ratios that are higher than the market over this period. Size is the one exception. However, even though Fama and French design their factor portfolios to represent plausible trading strategies, the last three columns of Table III show that even these strategies will differ considerably when it comes to real-world implementation. We perform three correlations, using Compustat data and the definitions from Ken French's data library. The first is the annual autocorrelation of the underlying characteristics used to form the portfolio. These range from 0.97 for size (market capitalization) down to 0.03 for reversal (trailing one-month return). What this means is that an annually rebalanced size tilt requires essentially zero turnover to maintain. Meanwhile, an annually rebalanced reversal portfolio requires a much higher rate of turnover. In the case of the monthly reversal and momentum factor portfolios, the turnover is greater than $100 \%$ per year.

A second challenge to implementing these trading strategies is liquidity. The third-to-last and second-to-last columns of Table III show the average cross-sectional rank correlation between each underlying characteristic and market capitalization, separately reported for stocks with above-median $(+)$ and below median (-) characteristics. A negative number means that a positive tilt requires buying smaller than average stocks in the Fama-French implementation of these factor portfolios: With the natural exception of size, characteristic correlations with market cap are negative for both above-median and below-median companies, meaning that the largest stocks fall in the middle of the characteristic distribution and are neither bought nor sold short. 
(For below median characteristics, we negate the characteristic value, to show the correlation with market capitalization of taking the opposite side from the basic characteristic, e.g., high beta, growth, large size, low profits, and so on.) In combination with a low autocorrelation, this suggests that the implementation costs of momentum and reversal are high, and the Sharpe ratios in the third and seventh columns of Table III need to be adjusted materially.

The returns on the first four characteristic portfolios were, to a great extent, achievable over the period from 1968 through 2014. The annual turnover is low enough not to materially change the gross returns in the first and fifth columns of Table III. We label these "Tilts." Meanwhile, the last three characteristic portfolios require significant turnover, involving small, less liquid stocks, and an implementation shortfall with any material level of assets under management. This is not to say that these are not still appealing strategies, but in an analysis of whether one tilt is subsumed by another, or an analysis of optimal allocations to these characteristic portfolios, implementation cannot safely be ignored. A careful analysis must include an assessment of the full time series of transaction costs, which will necessarily be dependent on the dollars to be invested, meaning that one size cannot fit all.

To be sure, transaction costs have fallen, so implementation costs are now more modest, but in the first half of the sample they were not trivial. And, as one might expect in a competitive market, this fall in transaction costs is accompanied by lower Sharpe ratios in the higher turnover strategies. The raw Sharpe ratio of the low growth (CMA) portfolio dropped from 0.76 in the first half of the sample to 0.54 in the second half. Meanwhile, momentum (MOM) dropped from 0.73 to 0.39 , and reversal (STREV) from 0.94 to 0.23 . We label these last three "Trades." Adjusting these for realistic trading costs is a useful exercise but beyond the scope of this paper. 
Figure 1 graphically depicts the information on autocorrelation and correlation with market capitalization in Table III. In Panel A, the seven characteristics are plotted along two dimensions. The vertical axis measures the annual autocorrelation of each underlying characteristic. The horizontal axis measures the correlation of each underlying characteristic with market capitalization, which is meant to proxy for implementation costs. (Average daily, dollar volume (-), bid-ask spread (+), and volatility $(+)$ are the underlying drivers of implementation shortfall in industrial models of trading costs, and all three have relatively high correlations with market capitalization.) The correlations are divided into the liquidity of positive (in blue) and negative (in red) tilts. We show thresholds of 0.5 correlation for both autocorrelation and liquidity correlation. Characteristic portfolios above or to the right of these thresholds have plausibly low implementation costs, while characteristic portfolios below and to the left may require nuanced trading strategies.

The upshot is that we can use the returns in Table III to assess the overlapping risks of the seven characteristic portfolios but not the average returns. For example, suppose that the low beta portfolio could be partially mimicked with a combination of low growth and momentum stocks. From a risk perspective, this is interesting. The low beta portfolio could then be judged as somewhat likely to underperform at the same time as the high profits portfolio and the momentum portfolio. However, the relative attractiveness of these two alternatives- the low beta tilt versus a blend of momentum and low growth trades — cannot be evaluated using the gross-of-transaction cost returns. For this reason, we focus our evaluation of risk on Tilts and Trades, and our evaluation of returns on Tilts alone.

Interestingly, Li, Sullivan, and Garcia-Feijóo (2014) argue that the raw performance of low risk is less impressive after transaction costs are considered, but it is worth noting that their 
analysis focuses on more transient measures of risk. Table III shows, by contrast, that beta is perhaps the most implementable tilt of the group, with an autocorrelation of 0.88 , and a combined size tilt in the tails of 0.31 . It is materially more persistent than value and profitability, with the same liquidity demands. It is less persistent than size but mechanically requires a much more modest cap tilt on the long side. Consistent with this conclusion, Baker, Bradley, and Wurgler (2011) and Auer and Schuhmacher (2015) find strong results in the value-weighted top 1000 stocks and the even the Dow 30, respectively. Growth, momentum, and reversal require much higher annual rebalancing.

\section{E. Correlations with Beta}

The final column in Table III shows how each of the seven tilts and trades correlates with beta in the cross-section. Low beta stocks, on average, have higher value scores. This lines up with the portfolio beta in the fourth column. The cross-sectional rank correlation with profits, growth, and reversal are essentially zero, despite these sorts producing a modest beta tilt in the fourth column. This suggests that generating a low beta tilt using trailing estimates of beta involves buying an entirely different set of stocks than tilts toward profits or trades that capitalize on low growth, even though the portfolio tilted towards higher profits or lower growth has a statistically significant beta tilt. And, the cross-sectional correlation between the trailing estimate of beta with market capitalization and momentum go in the opposite direction of the portfolio betas, again indicating no practical overlap in the stock selection strategies. 


\section{F. Fixed Income}

We also include two credit market portfolios, largely as controls. The first is the return on long-term government bonds to capture the effect of interest rate movements and the premium for bearing that risk, which we label Duration. The second is the difference between the return on investment grade corporate bonds minus the return on long-term government bonds to capture the effect of credit risk movements and the associated risk premium, which we label Credit. Notably, the duration portfolio has been linked to the returns of low beta and profitable stocks, e.g. Baker and Wurgler (2012). We also remove the average market tilts in these portfolios, so the analyses in this paper can be considered as tilts away from a value-weighted equity market portfolio, through characteristic and fixed income portfolios.

\section{The Risks of Low Risk: Is Low Risk Subsumed by Value, Size, Profitability, and the Bond Market?}

Before turning to the main exercise of computing mean-variance optimal tilts in the next section, we examine the incremental value of a low risk tilt. Empirical studies of risk and return date back at least to the 1970s and Black (1972), Jensen, Black, and Scholes (1972), and Haugen and Heins (1975). More recent work, including Fama and French (1992), Ang, Hodrick, Xing, and Zhang (2006, 2009), Blitz and van Vliet (2007), Baker, Bradley, and Wurgler (2011), Baker, Bradley, and Taliaferro (2014), and Frazzini and Pedersen (2014) use more updated data, global markets, other asset classes beyond equities, and a broader set of risk measures, including idiosyncratic risk. The upshot of all of these papers is that risk and return are at most weakly related. 


\section{A. Low Risk Discontents}

Some scholars have challenged the practical relevance of these findings. It is not that the seminal papers got the empirics wrong, but rather that the results are subsumed by even more fundamental drivers of return, notably value and profitability. For example, Shah (2011) and Crill (2014) argue in white papers that the performance of risk-tilted portfolios comes from the correlation between value and beta, and much of that performance comes from the periods where the two characteristics align. Novy-Marx (2014) emphasizes profitability instead of value. These are both autocorrelated characteristics like beta and tilts, which we examine below. These papers do not resolve the puzzle, but rather they suggest that value and profitability are alternatives that deliver the same or better outcomes. We come to a rather different conclusion, which we summarize below.

A third paper by Bali, Brown, Murray, and Tang (2014) makes a more surprising claim that the low risk tilt is subsumed by the maximum daily return from the previous month, which has a much lower autocorrelation, placing it clearly in the category of a trade that has been profitable over the full sample period on a raw basis, but here, execution costs loom large relative to the mean return.

There is of course a large literature that considers whether a measure like beta is an appropriate risk measure. That literature is much too long to survey here, so we simply say that the arguments contained there are relevant for a mean-variance optimizing investor, though we do briefly consider the downside risk. 


\section{B. The Risks of Low Risk}

A first question is how much of the month-to-month variation in low beta returns is explained by other characteristic portfolios. The variance of the low beta returns is $107 \%^{2}$, which is equal to standard deviation of $10 \%$ in Table III squared. Notably, $41 \%$ of this variance is explained, while the remaining 59\% is unexplained. We perform this analysis with a set of univariate and multivariate regressions of the time series returns summarized in Table III.

The results are shown in Table V. The univariate stock characteristic effects are intuitive. For example, when low beta stocks underperform on a market-adjusted basis, so too do larger stocks, value stocks, profitable stocks, and stocks with lower asset growth. These are what one might intuitively call the more boring, and less risky stocks on average. In the fourth column of Table III, the beta tilts of these portfolios line up correspondingly. While the market effects have been removed, the results in Table V suggest that residual returns remain a common component across these various portfolios. Momentum and reversal explain less risk on average. Momentum is an interesting case. Unlike the more persistent characteristics, momentum tends to occasionally line up with high beta stocks_-for example, in the late 1990s in a rapidly rising equity market — and with low beta stocks during a market correction like the fall of 2008 and the spring of 2009. So it is hard to think of momentum as a stable risk factor. Momentum instead inherits the risk of whatever characteristics have been in favor of late. None of these factor portfolios on its own explains more than $17 \%$ of the risk of the low beta portfolio.

The fixed income effects are also intuitive. Low beta stocks are more 'bond-like' and investors may view them, rationally or not, as closer substitutes for long-term government bonds. This is a comparatively large effect, explaining $10 \%$ of the risk of the low beta portfolio. The 
effect of credit is smaller, but in the expected direction. Narrowing credit spreads might indicate a rise in risk appetite and hence weaker performance of low risk stocks.

The covariances of the six characteristic portfolios and two fixed income portfolios overlap. For example, high profit firms tend to grow more slowly and trade at lower multiples. So the sum of the univariate effects is more than the combined explanatory power. The Column 9 of Table V shows a multivariate attribution of the returns of the low beta portfolio. Most of the univariate effects carry over. Value stocks, large stocks, profitable stocks, slow growing stocks, and duration still explain the low beta returns as before. Momentum becomes slightly stronger statistically, while reversal remains weak. Credit changes sign, suggesting that once the returns of the other characteristic portfolios are taken into account, low beta stocks tend to perform better when credit spreads are widening, but this is very small by comparison. The multivariate regression allows us to put a point estimate on the ability of these seven portfolios to mimic the risks of low beta portfolios at $41 \%$. Figure 2 summarizes the shared risks of the beta portfolio.

We also consider the overlap in downside risk. We measure the drawdown of the portfolios in Table III along with the two fixed income portfolios. A drawdown is the return since a prior high water mark. The largest drawdowns of the low beta portfolio occur during rising markets in the late 1990s and 2009. Figure 3 lines these up with drawdowns in the other characteristic and fixed income portfolios. For example, the performance of value and low beta line up almost perfectly in the late 1990s and then not at all in 2009. There is a similar pattern for high profit firms. Momentum suffers a historic drawdown in 2009 that lines up with low beta, but otherwise there is no apparent correlation. The bottom line in Figure 3 is that the average relationships shown in Table V and Figure 2 are not especially robust, and a single episode of correlated poor or strong performance can overshadow what is otherwise a weak relationship. 


\section{The Returns of Low Risk}

A second question is, how much of the average return of the low beta portfolio is explained by other characteristic portfolios? The average alpha of the low beta portfolio is $6.4 \%$. Here, the takeaway is that $47 \%$ of this risk-adjusted return is explained by other characteristic tilts. The remaining 53\% is unexplained. We again perform this analysis with a set of univariate and multivariate regressions of the time series returns summarized in Table III.

The results are shown in Table VI. This table takes the coefficients from Table V and multiplies them by the market-neutral return of each strategy to measure the portion of the market-neutral low beta portfolio return that is explained by each characteristic tilt. For example, because value has an annualized market-neutral return of 5.7\% per year and the low beta portfolio has a loading of 0.31 on this portfolio, the part of the low beta return that overlaps with value is $1.8 \%$. The total annualized market-neutral return on the low beta tilted portfolio is $6.4 \%$, so $1.8 \%$ represents $28 \%$ of the total alpha. Similar calculations can be done for high profits and duration, which overlap by $1.9 \%$ and $1.0 \%$, respectively. The impact of size and credit are smaller. The multivariate regression takes into account the union of these overlapping portfolios. In all, the three characteristic tilts and the two fixed income portfolios have market-neutral returns that overlap $3.0 \%$ out of the $6.4 \%$ alpha for the low beta tilt, or $47 \%$ of the average alpha of the low beta portfolio.

It is important to note that we excluded the high turnover, high liquidity demand characteristic portfolios because their Sharpe ratios are not fully implementable, and so the mimicking portfolio approach that is implicit in these regressions would overstate the extent to which low growth, momentum, and reversal are able to explain the returns to low beta. The analysis of risk says that there is a considerable portion of low beta that cannot be captured by 
other means, and the analysis of return says that there is no sense in which the returns of low risk can be reproduced with similar risk and return characteristics with a portfolio of other tilts. At least $53 \%$ of the low risk anomaly remains after other tilts are taken into consideration. Going a bit further, the correlations at the level of characteristics provide additional emphasis. For example, the characteristic correlation of low beta with high profits is exactly zero, meaning that the overlapping risk and returns are not coming from holding the same stocks, but rather holding different stocks that have overlapping return patterns. This is an important note for capacity. Even if the return series were identical, splitting the tilt between high profits and low beta would economize on transaction costs, assuming that the price impact of trade is convex.

\section{Why a Different Conclusion?}

We find that there is an economically and statistically significant alpha of $3.6 \%$ after taking into account tilts toward value, size, profitability, duration, and credit. The t-statistic is 3.1, which is higher than an equivalent decomposition of Fama-French's HML or RMW, with the remaining tilts. Other research has come to a very different conclusion. For example, Crill (2014) concludes that "low market beta stocks received a return boost due to a value tilt over the past few decades. The historical average returns to low market beta stocks are well-explained by known drivers of returns.” And Novy-Marx (2014) argues that “the performance of defensive equity strategies is explained by known drivers of cross-sectional variation in returns... earlier work fails to account for profitability, however, which is an essential ingredient for understanding defensive strategy performance.” A natural question is, why do we come to a different conclusion? 
Measurement of risk. The measure of beta is important, not for the direction of the results, but in terms of economic size and statistical significance. A simple, five-year monthly beta does not deliver the same risk reduction as more powerful estimates of covariance. The results here use five-years of overlapping three-day returns, and a higher frequency estimate of volatility. This produces a measure of beta that reduces risk in quintile portfolios by $22 \%$ more, with a spread that drops from -0.86 to -1.05 in Table II. The resulting measure of beta has no cross-sectional correlation with profitability. It also tilts small. While this may increase its implementation costs somewhat, it puts the measure of risk on equal footing with the other tilts and trades. As shown in Table III, the resulting measure of beta leads to portfolios that have a similar tilt towards small stocks in the long and short tails.

Portfolio construction. The method of portfolio construction is also important. Our approach seems the simplest and most sensible. For any given characteristic, use the same approach. If the alternative, or left-hand-side portfolios, allow shorting or tilt small, so too should the low-risk-tilted portfolio. We follow the exact same procedure for the low risk portfolio as Fama and French detail for HML and RMW. It is widely known that anomalies tend to be stronger in smaller, less liquid stocks with higher bid-ask spreads, and often stronger on the short side than the long side. For example, see Zhang (2006) or Hong, Lim, and Stein (2000). Pitting a value-weighted managed volatility portfolio against one that divides the portfolio equally, as Fama and French HML and RMW do, into long and short bets in small and large stocks, will stack the deck against a low risk tilt. Pitting a long-only managed volatility portfolio against an HML portfolio that is both long and short will of course also stack the deck against a low risk tilt. 
Characteristics versus covariances. The factor loadings in regressions like those in Table III and IV show the overlap in the return performance of tilts and trades. They do not prove that the underlying strategies overlap to the same extent. For example, a US value strategy may overlap considerably, measured by the covariance of returns, with a non-US value strategy. But, by definition, the overlap in the underlying portfolios is zero. They are drawn from entirely different universes. And yet, if value were a useful predictor of returns, it would be foolish to pursue value only in one geographic area. So it goes for low risk. The characteristic correlation with profitability and value is quite low, even though there is some overlap in returns. Even the overlap in returns appears concentrated in a single episode in Figure 3.

Tilts versus trades. A final issue, and the main emphasis of our analysis, is that care is needed in benchmarking tilts with much higher frequency trades. For example, Bali, Brown, Murray, and Tang (2014) use a measure of lottery preferences that has essentially zero autocorrelation at an annual horizon. Meanwhile, the autocorrelation of beta is close to 0.9.

When these issues are handled in a sensible way, low risk survives and survives easily. This is not to say that value and profitability have not been important predictors of returns over the period from 1968 through 2014, but they are far from subsuming a low risk tilt.

\section{Optimal Tilts, 1968-2014}

With a somewhat lengthy setup complete, we can now turn our attention to computing the optimal tilts over the period from 1968 through 2014, with an exercise of simple mean variance analysis. The starting point is four equity tilts plus two fixed income portfolios. We use the monthly in-sample correlation matrix and portfolio volatilities to measure risk. And we use 
the in-sample average returns to measure return. The question is what combination of these six portfolios would have produced the highest Sharpe ratio over this period.

\section{A. Mean-variance analysis}

Table VII shows the inputs to the analysis. Starting in the second column, we reproduce the average, market-neutral returns from Table III, and we also express these per unit of standard deviation in monthly returns. These range from $-0.3 \%$ per standard deviation, per year for the credit portfolio to $2.2 \%$ for low beta. The last six columns show the in-sample correlations. The beta correlations will be familiar from the results of Table VI. The low beta tilts have a positive correlation in returns with value, profits, and duration, and a negative correlation with size and credit.

The optimal blend of these six portfolios produces an average return per standard deviation of 3.3\%, indicating an annual Sharpe ratio of 1.0. The interesting part is the weights in the first column. A high allocation of the risk budget goes to the low risk tilt. Despite its low Sharpe ratio, the highest allocation is the small size portfolio. The reasons for this are evident in the correlation matrix. Size is negatively correlated with all but credit, and it has a meaningfully large and negative correlation with both low beta and high profits. This means that the allocation to size, despite its own low Sharpe ratio, allows a greater tilt toward low beta and high profits in particular. Next is high profits and value, with much lower weights allocated to the two fixed income portfolios. 


\section{B. Some example implications}

It is not worth attaching too much significance to the specific weights in Table VII. For example, with an equal allocation to the four tilts, the return falls by only one basis point. Another way of transforming these tilts is to consider how many dollars would have been devoted to each of the market-neutral portfolios to add a $1 \%$ monthly standard deviation tilt to produce $3.3 \%$ additional return. Note that a $1 \%$ monthly standard deviation is equivalent to $3.5 \%$ per year. A $27 \%$ tilt toward a standardized $1 \%$ standard deviation low beta portfolio is equivalent to putting $\$ 0.085$ per dollar in the overall portfolio into the low beta tilt, which equals $2.3 \%$ divided by $7.3 \%$ times $27 \%$. Another $\$ 0.068$ goes to value, $\$ 0.086$ goes to small size, and $\$ 0.101$ goes to high profits. We leave them as percentage tilts in Table VII, because the exact scale depends on the tolerance for tracking error.

These are market-neutral portfolios, where the in-sample average market effects have been hedged, so that the beta is exactly zero. As a result, these can be thought of as overlays onto a static allocation. For example, the $\$ 0.085$ invested in the low beta tilt can be decomposed into $\$ 0.085$ invested in a long-short portfolio in low beta stocks and $\$ 0.072$ invested in additional equity at market weights - through futures or swaps, or simply by increasing the allocation to equities in the static allocation. (The extra $\$ 0.072$ in equity is equal to $\$ 0.085$ times the beta of the long-short portfolio of -0.84 times -1 .) The other adjustments are smaller, because the betas in Table III for value, small size, and high profits are closer to zero. All told, at the optimal allocations to the four equity portfolios, there is an increase in the static allocation to equities of $\$ 0.079$. This means the canonical 60/40 portfolio becomes 68/32. 


\section{Conclusion}

Asset pricing anomalies can be divided into those that are relatively straightforward to implement, because of high autocorrelation or large capitalization and liquid long and short positions. We call these tilts. We compute the optimal allocation to four tilts over the period from 1968 through 2014. Value, small size, high profits, and low beta all get positive exposures; they are $19 \%, 26 \%, 22 \%$, and $27 \%$, respectively. The large allocation to low beta stands in contrast to recent papers by Novy-Marx (2014) and others, which claim that low risk strategies are subsumed by value or high profits. We find different results with a more predictive measure of beta, with a consistent, long-short portfolio construction that treats the strategies on an apples-toapples basis, and by separating out tilts from higher frequency trades.

Lower autocorrelation and less liquid anomalies also have a part in stock selection, but their optimal allocations are much more sensitive to portfolio size. Reasonable estimates of transaction costs, which are dependent on assets under management, must be deducted from the average returns, to provide rough estimates of their allocations alongside lower cost tilts. 


\section{References}

Ang, Andrew, Robert J. Hodrick, Yuhang Xing, and Xiaoyan Zhang. "The cross-section of volatility and expected returns." The Journal of Finance 61, no. 1 (2006): 259-299.

Ang, Andrew, Robert J. Hodrick, Yuhang Xing, and Xiaoyan Zhang. "High idiosyncratic volatility and low returns: International and further US evidence." Journal of Financial Economics 91, no. 1 (2009): 1-23.

Auer, Benjamin R., and Frank Schuhmacher. "Liquid Betting against Beta in Dow Jones Industrial Average Stocks." Financial Analysts Journal 71, no. 6 (2015): 30-43.

Baker, Malcolm, Brendan Bradley, and Ryan Taliaferro. "The Low-Risk Anomaly: A Decomposition into Micro and Macro Effects." Financial Analysts Journal 70, no. 2 (2014): 4358.

Baker, Malcolm, Brendan Bradley, and Jeffrey Wurgler. "Benchmarks as limits to arbitrage: Understanding the low-volatility anomaly." Financial Analysts Journal 67, no. 1 (2011): 40-54.

Baker, Malcolm, and Jeffrey Wurgler. "Comovement and predictability relationships between bonds and the cross-section of stocks." Review of Asset Pricing Studies 2, no. 1 (2012): 57-87.

Bali, Turan G., Stephen Brown, Scott Murray, and Yi Tang. "Betting against beta or demand for lottery." Georgetown McDonough School of Business Research Paper 2408146 (2014).

Banz, Rolf W. "The relationship between return and market value of common stocks." Journal of Financial Economics 9, no. 1 (1981): 3-18.

Basu, Sanjoy. "The relationship between earnings' yield, market value and return for NYSE common stocks: Further evidence." Journal of financial economics 12, no. 1 (1983): 129-156.

Black, Fischer. "Capital market equilibrium with restricted borrowing." Journal of Business (1972): 444-455.

Jensen, Michael C., Fischer Black, and Myron S. Scholes. "The capital asset pricing model: Some empirical tests." (1972).

Blitz, David, and Pim Van Vliet. "The volatility effect: Lower risk without lower return." Journal of Portfolio Management (2007): 102-113.

Chan, Louis KC, Yasushi Hamao, and Josef Lakonishok. "Fundamentals and stock returns in Japan." The Journal of Finance 46, no. 5 (1991): 1739-1764.

Cohen, Randolph B., Paul A. Gompers, and Tuomo Vuolteenaho. "Who underreacts to cash-flow news? Evidence from trading between individuals and institutions." Journal of Financial Economics 66, no. 2 (2002): 409-462. 
Cooper, Michael J., Huseyin Gulen, and Michael J. Schill. "Asset growth and the cross-section of stock returns." The Journal of Finance 63, no. 4 (2008): 1609-1651.

Crill, Wes. “Low Volatility Strategies,” unpublished white paper, Dimensional Fund Advisors (2014).

Daniel, Kent, and Sheridan Titman. "Market reactions to tangible and intangible information." The Journal of Finance 61, no. 4 (2006): 1605-1643.

Fama, Eugene F., and Kenneth R. French. "The cross-section of expected stock returns." The Journal of Finance 47, no. 2 (1992): 427-465.

Fama, Eugene F., and Kenneth R. French. "Common risk factors in the returns on stocks and bonds." Journal of Financial Economics 33, no. 1 (1993): 3-56.

Fama, Eugene F., and Kenneth R. French, “Industry costs of equity.” Journal of Financial Economics 43 (1997): 153-193.

Fama, Eugene F., and Kenneth R. French. "Profitability, investment and average returns." Journal of Financial Economics 82, no. 3 (2006): 491-518.

Fama, Eugene F., and Kenneth R. French, “A five-factor asset pricing model.” Journal of Financial Economics 116 (2015): 1-22.

Frazzini, Andrea, and Lasse Heje Pedersen. "Betting against beta." Journal of Financial Economics 111, no. 1 (2014): 1-25.

Haugen, Robert A., and Nardin L. Baker. "Commonality in the determinants of expected stock returns." Journal of Financial Economics 41, no. 3 (1996): 401-439.

Haugen, Robert A., and A. James Heins. "Risk and the rate of return on financial assets: Some old wine in new bottles." Journal of Financial and Quantitative Analysis 10, no. 05 (1975): 775784.

Hirshleifer, David, Kewei Hou, Siew Hong Teoh, and Yinglei Zhang. "Do investors overvalue firms with bloated balance sheets?" Journal of Accounting and Economics 38 (2004): 297-331.

Hong, Harrison, Terence Lim, and Jeremy C. Stein. "Bad news travels slowly: Size, analyst coverage, and the profitability of momentum strategies." The Journal of Finance 55, no. 1 (2000): 265-295.

Jegadeesh, Narasimhan. "Evidence of predictable behavior of security returns." Journal of Finance (1990): 881-898.

Jegadeesh, Narasimhan, and Sheridan Titman. "Returns to buying winners and selling losers: Implications for stock market efficiency." The Journal of Finance 48, no. 1 (1993): 65-91. 
Jegadeesh, Narismhan, and Sheridan Titman. "Short-hoirzon return reversals and the bid-ask spread.” Journal of Financial Intermediation 4 (1995a): 116-132.

Jegadeesh, Narismhan, and Sheridan Titman. “Overreaction, delayed reaction, and contrarian profits.” Review of Financial Studies 8 (4) (1995b): 973-993.

Jensen, Michael C., Fischer Black, and Myron S. Scholes. "The capital asset pricing model: Some empirical tests." (1972).

Li, Xi, Rodney N. Sullivan, and Luis Garcia-Feijóo. "The limits to arbitrage and the lowvolatility anomaly." Financial Analysts Journal 70, no. 1 (2014): 52-63.

Loughran, Tim, and Jay R. Ritter. "The new issues puzzle." The Journal of Fnance 50, no. 1 (1995): 23-51.

Novy-Marx, Robert. "The other side of value: The gross profitability premium." Journal of Financial Economics 108, no. 1 (2013): 1-28.

Novy-Marx, Robert. "Predicting anomaly performance with politics, the weather, global warming, sunspots, and the stars." Journal of Financial Economics 112, no. 2 (2014): 137-146.

Pontiff, Jeffrey, and Artemiza Woodgate. "Share Issuance and Cross-sectional Returns." The Journal of Finance 63, no. 2 (2008): 921-945.

Ritter, Jay R. "The long-run performance of initial public offerings." The Journal of Finance 46, no. 1 (1991): 3-27.

Rogerscasey, “Genius Beta: Why Settle for Just 'Smart’ Beta?” Investment Focus, June 2015.

Rosenberg, Barr, Kenneth Reid, and Ronald Lanstein. "Persuasive evidence of market inefficiency." The Journal of Portfolio Management 11, no. 3 (1985): 9-16.

Shah, Ronnie. “Understanding Low Volatility Strategies: Minimum Variance,” unpublished white paper, Dimensional Fund Advisors (2011).

Sloan, R. "Do stock prices fully reflect information in accruals and cash flows about future earnings? (Digest summary)." Accounting Review 71, no. 3 (1996): 289-315.

Stambaugh, Robert F., Jianfeng Yu, and Yu Yuan. "The short of it: Investor sentiment and anomalies." Journal of Financial Economics 104, no. 2 (2012): 288-302.

Titman, Sheridan, Kuo-Chiang Wei, and Feixue Xie. "Capital investments and stock returns." Journal of Financial and Quantitative Analysis 39, no. 04 (2004): 677-700.I 
Xing, Yuhang. "Interpreting the value effect through the Q-theory: An empirical investigation." Review of Financial Studies 21, no. 4 (2008): 1767-1795.

Zhang, X. "Information uncertainty and stock returns." The Journal of Finance 61, no. 1 (2006): 105-137. 
Figure 1. Implementation of Tilts and Trades. We compute the annual autocorrelation of firm characteristic values, and the correlation of firm characteristic values with market capitalization. For correlation with market capitalization, we separately estimate correlations for stocks with above-median characteristic values (blue) and below-median characteristic values (red), where we negate the characteristic for below-median stocks. In the first panel, we examine the Fama-French factors, along with momentum, reversal, and beta. In the second panel, we examine 55 microfactors tracked by Acadian Asset Management, a quantitative investment management firm. Values above the horizontal axis require relatively low turnover. We label these "Tilts." Values below the horizontal axis and to the right of the vertical axis require turnover in relatively liquid names. Values below the horizontal axis and to the left of the vertical axis require turnover in relatively illiquid names. We label these liquid and illiquid "Trades."

Panel A. Fama French Factors and Low Beta

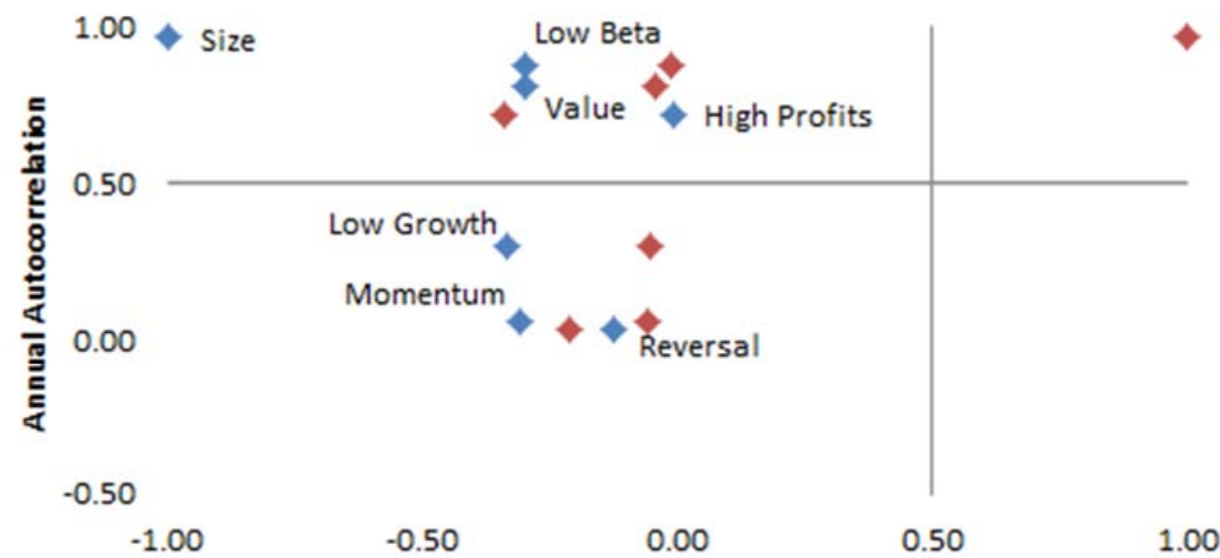

Correlation with Market Capitalization

- Negative Characteristic Value $\quad$ Positive Characteristics Values

Panel B. Acadian Asset Management Microfactors

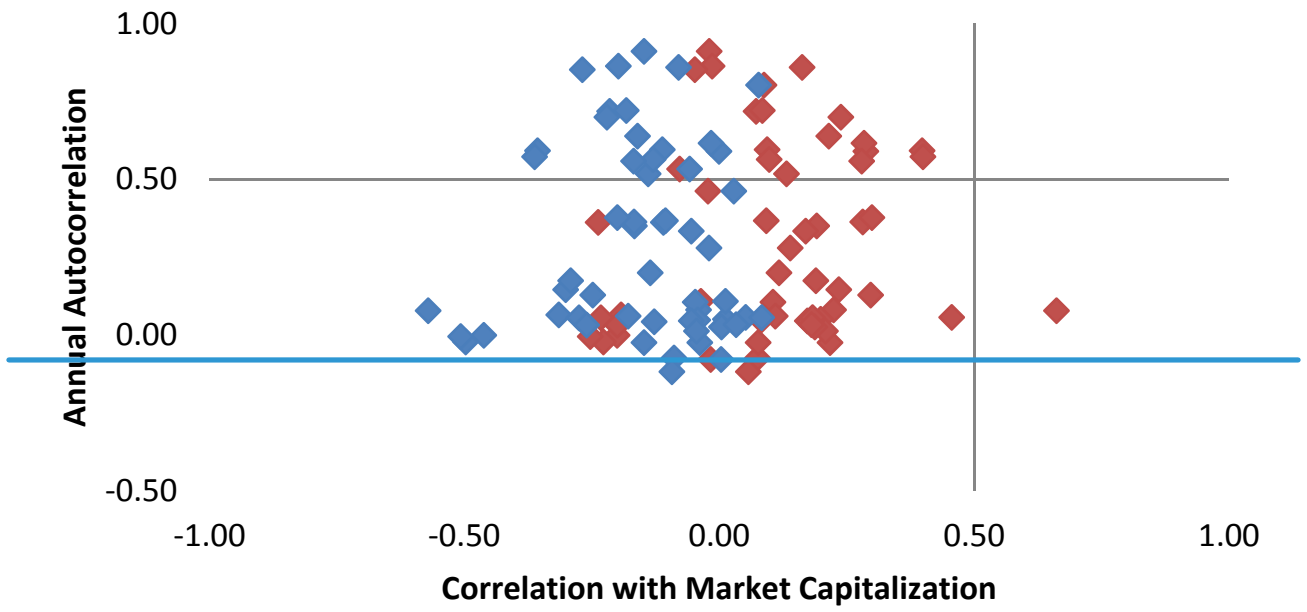

$\diamond$ Negative Characteristic Value $\quad$ Positive Characteristic Value 
Figure 2. Shared Risk in Beta Tilts, 1968-2014. We decompose the variance of a long-short beta portfolio into components shared by: value, size, and profit tilts; growth, momentum, and reversal trades; and bond market measures of duration and credit. Each strategy is orthogonalized to the overall equity market. The remaining variance is unique to a beta tilt. See Table V.

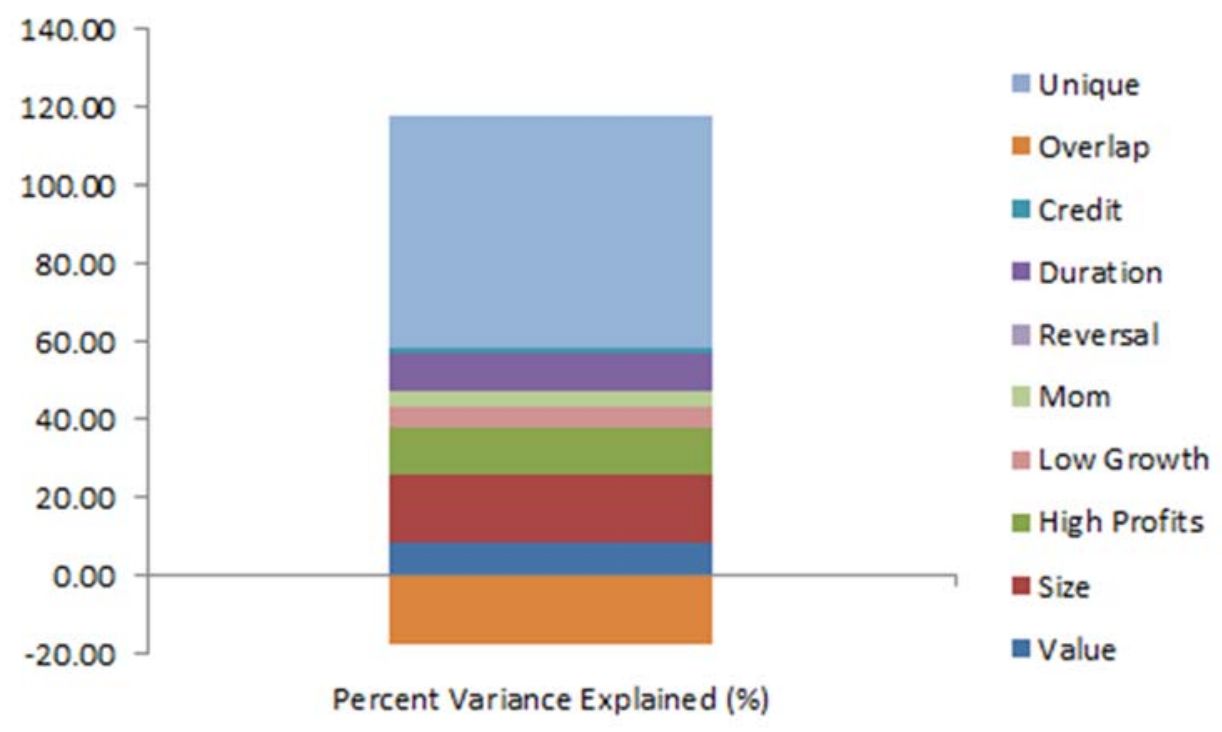


Figure 3. Shared Drawdown Risk in Beta Tilts, 1968-2014. We superimpose the drawdowns of a long-short beta portfolio onto the drawdowns of: the overall equity market; value, size, and profit tilts; growth, momentum, and reversal trades; and bond market measures of duration and credit. Each strategy is orthogonalized to the overall equity market.
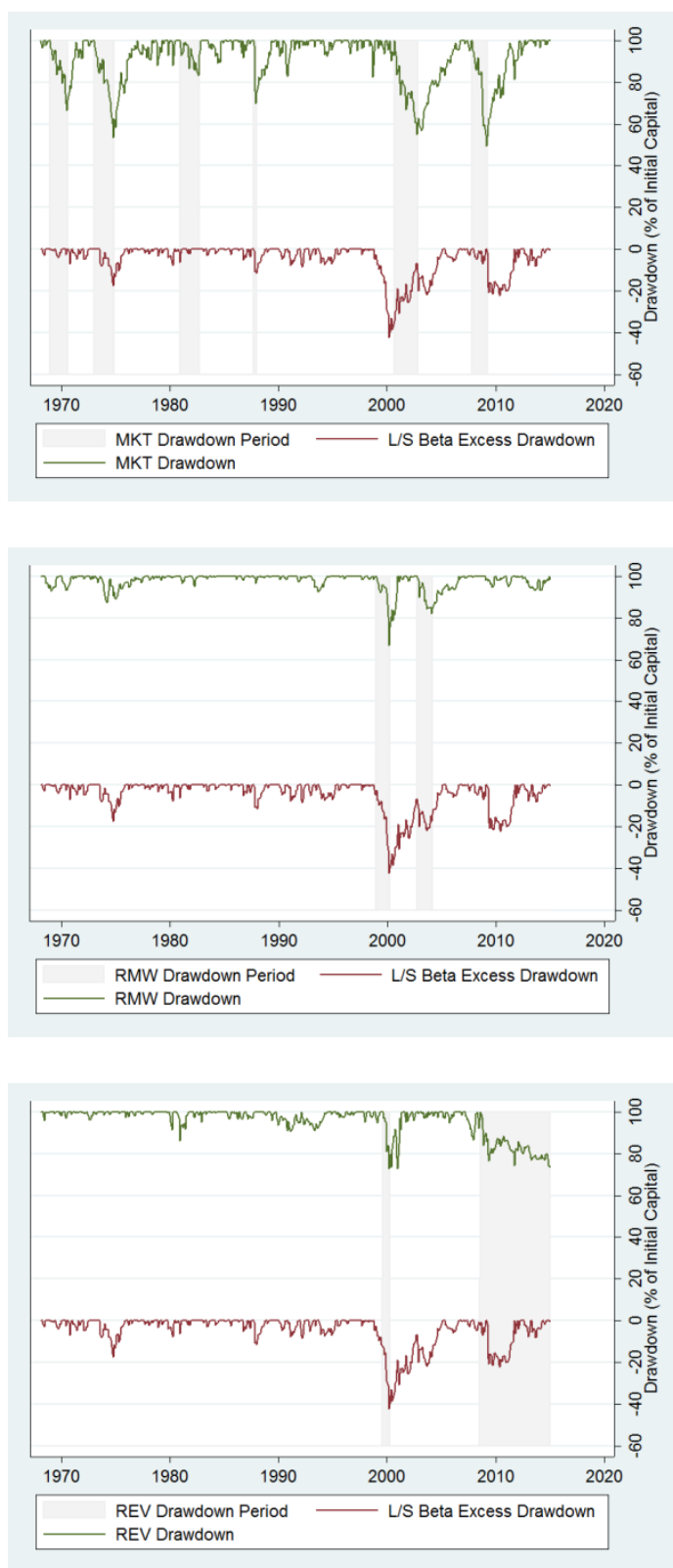
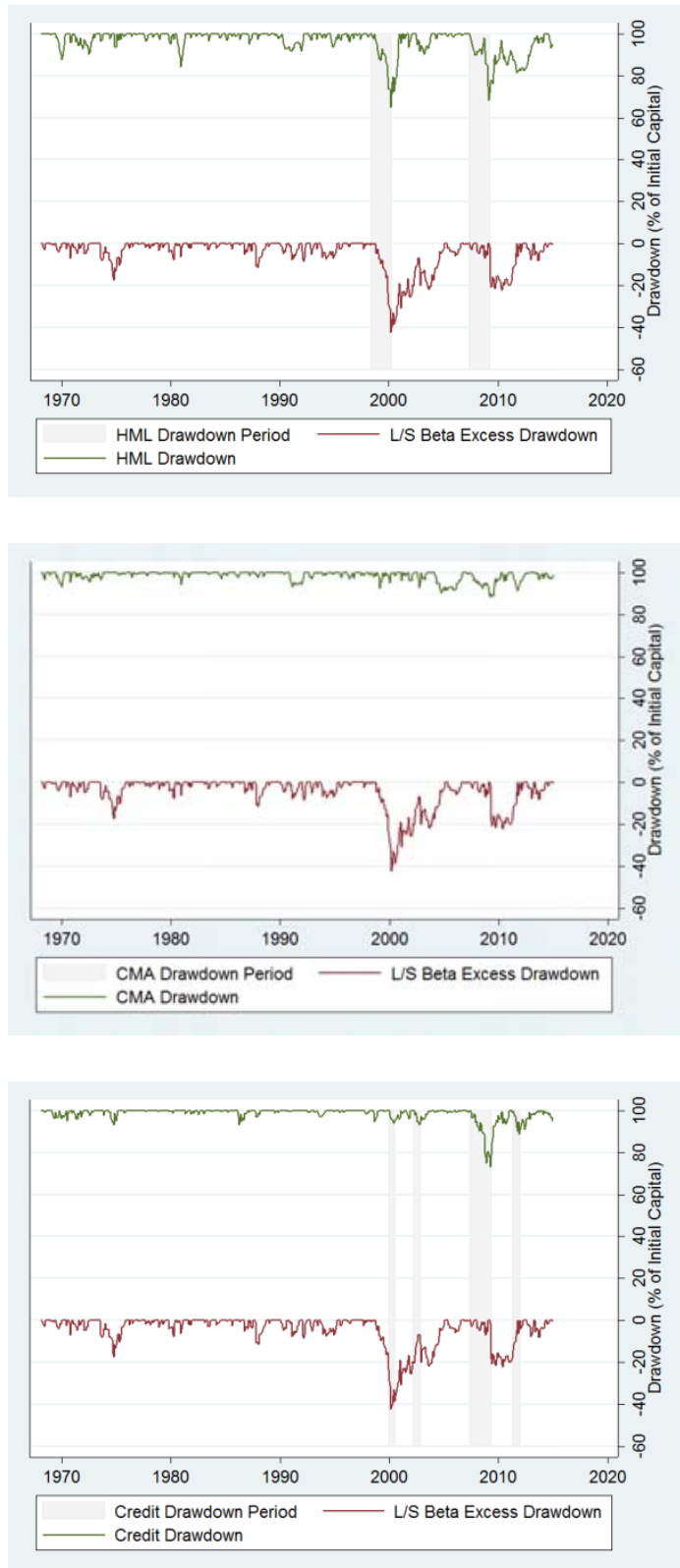
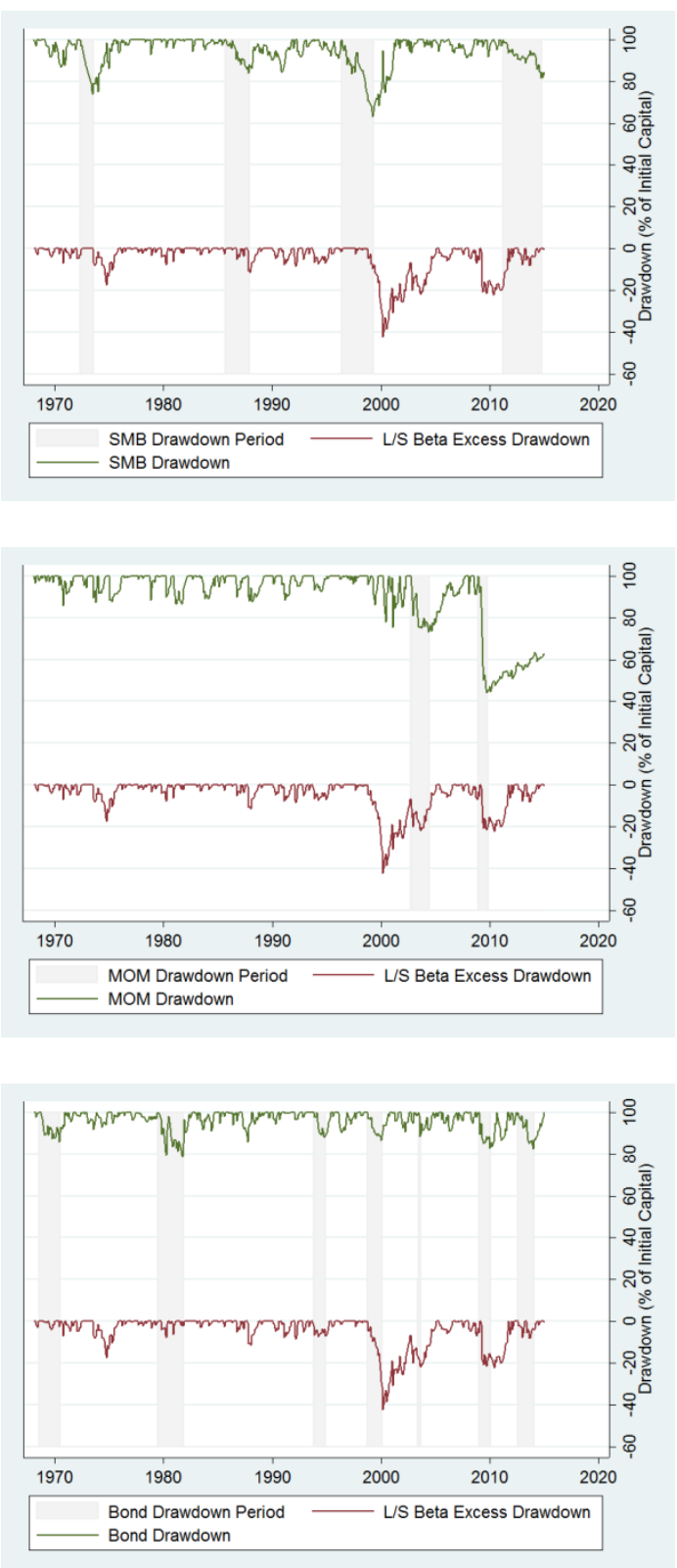
Figure 4. Sources of Return in Beta, 1968-2014. We decompose the return on a long-short beta portfolio into components shared by: value, size, and profit tilts; and bond market measures of duration and credit. Each strategy is orthogonalized to the overall equity market. The remaining return is unique to a beta tilt. See Table VI.

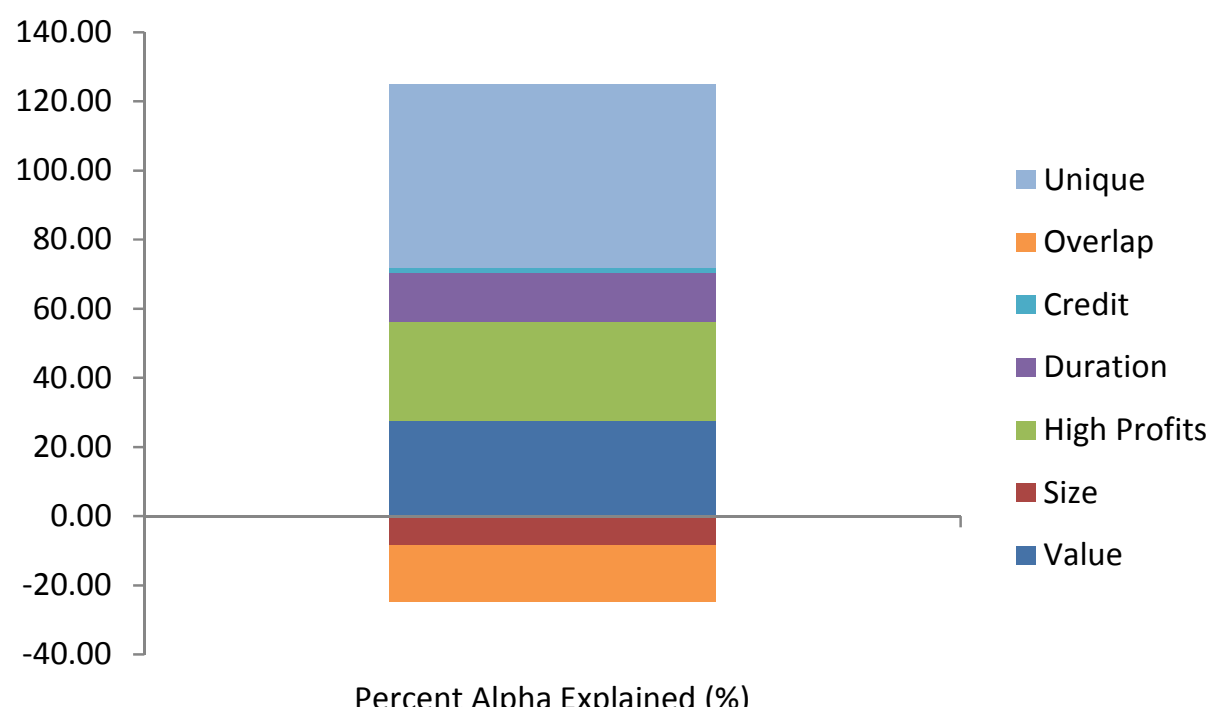


Figure 5. Optimal Tilts, 1968-2014. We compute the mean-variance optimal tilts using in-sample measures of correlation, standard deviation, and annualized return. Tilts include: value, size, and profit tilts; and bond market measures of duration and credit. Each strategy is orthogonalized to the overall equity market. See Table VII.

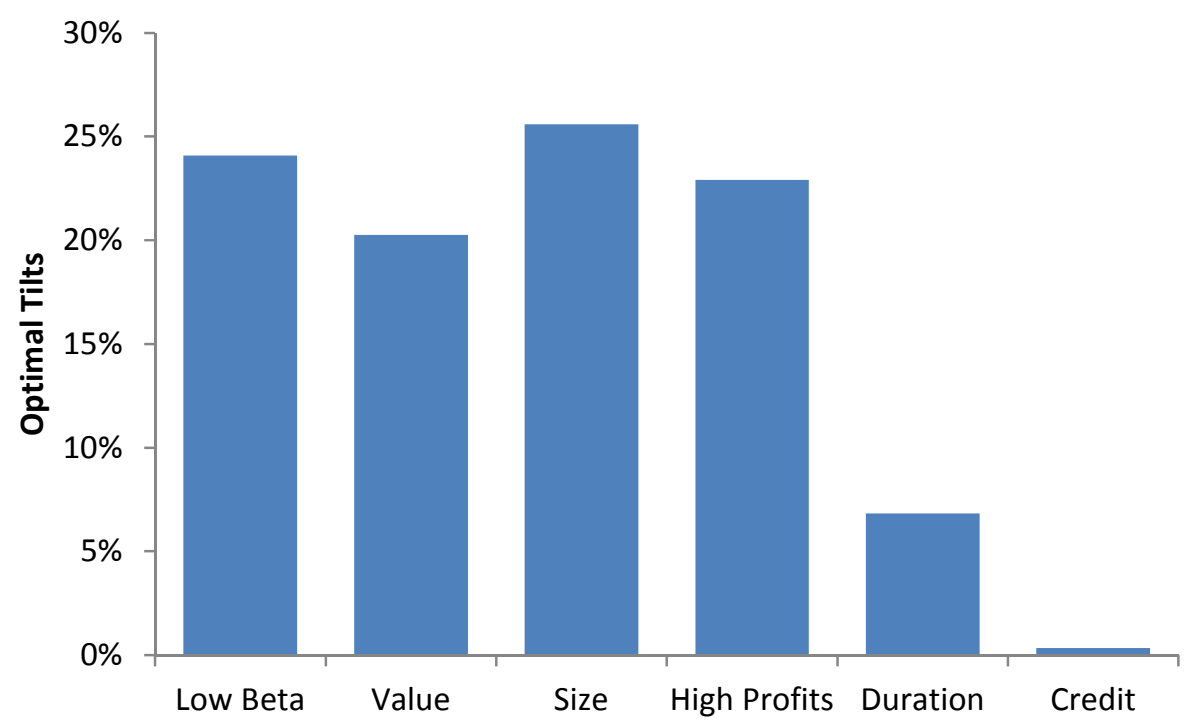


Table I. Sample Characteristic Tilts and Trades. We examine seven stock characteristics that appear in the literature on capital market anomalies.

\begin{tabular}{|c|c|}
\hline Characteristic & Example Publications \\
\hline $\begin{array}{l}\text { Low Beta } \\
\text { 5-Year, 3-Day Overlapping Window Correlation } \\
\text { 1-Year, Daily Volatility }\end{array}$ & $\begin{array}{l}\text { Jensen, Black, and Scholes, } 1972 \\
\text { Baker, Bradley, and Wurgler, } 2011 \\
\text { Frazzini and Pedersen, } 2014\end{array}$ \\
\hline $\begin{array}{l}\text { Value } \\
\text { Book Equity / } \\
\text { Price times Shares Outstanding }\end{array}$ & $\begin{array}{l}\text { Rosenberg, Reid, and Lanstein, } 1985 \\
\text { Chan, Hamao, and Lakonishok, } 1991 \\
\text { Fama and French, } 1992\end{array}$ \\
\hline $\begin{array}{l}\text { Small Size } \\
\text { Price times Shares Outstanding }\end{array}$ & Banz, 1981 \\
\hline $\begin{array}{l}\text { High Profits } \\
\text { Revenues - COGS - Interest - SG\&A / } \\
\text { Book Equity }\end{array}$ & $\begin{array}{l}\text { Novy-Marx, } 2010 \\
\text { Basu, } 1983 \\
\text { Haugen and Baker, } 1996 \\
\text { Cohen, Gompers, and Vuolteenaho, } 2002 \\
\text { Novy-Marx, } 2013 \\
\text { Fama and French, } 2006 \\
\text { Chen, Novy-Marx, and Zhang, } 2010 \\
\text { Wang and Yu, } 2010\end{array}$ \\
\hline \multirow[t]{4}{*}{$\begin{array}{l}\text { Low Growth } \\
\text { Assets /Assets, Lagged } 1 \text { Year }\end{array}$} & $\begin{array}{l}\text { Firms with high equity issuance underperform } \\
\text { Ritter, } 1991 \\
\text { Loughran and Ritter, } 1995 \\
\text { Pontiff and Woodgate, } 2006 \\
\text { Daniel and Titman, } 2006 \\
\text { Ikenberry, Lakonishok, and Vermaelen, } 1995\end{array}$ \\
\hline & $\begin{array}{l}\text { Firm with high accruals underperform } \\
\text { Sloan, } 1996\end{array}$ \\
\hline & $\begin{array}{l}\text { Firms with high asset growth underperform } \\
\text { Hirshleifer, Hou, Teoh, and Zhang, } 2004 \\
\text { Cooper, Gulen, and Schill, } 2008\end{array}$ \\
\hline & $\begin{array}{l}\text { Firms with high investment underperform } \\
\text { Titman, Wei, and Xie, } 2004 \\
\text { Xing, } 2008 \\
\text { Fairfield, Whisenant, and Yohn, } 2003\end{array}$ \\
\hline $\begin{array}{l}\text { Momentum } \\
\text { Return from } 12 \text { Months Ago to } \\
\text { One Month Ago }\end{array}$ & $\begin{array}{l}\text { Stock market winners outperform } \\
\text { Jegadeesh, } 1990 \\
\text { Jegadeesh and Titman, } 1993\end{array}$ \\
\hline $\begin{array}{l}\text { Reversal } \\
\text { Return from the Previous Month }\end{array}$ & $\begin{array}{l}\text { Stock market losers outperform } \\
\text { Jegadeesh, } 1990 \\
\text { Jegadeesh and Titman, 1995a, b }\end{array}$ \\
\hline
\end{tabular}


Table II. Beta Measures, 1968-2014. We examine the predictive power of three different measures of beta. The first uses up to five years of monthly data, with a

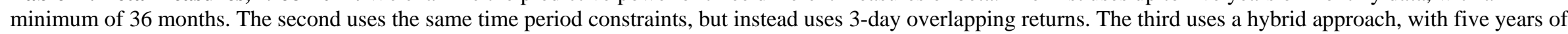

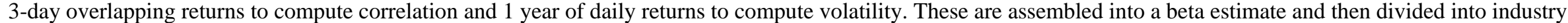

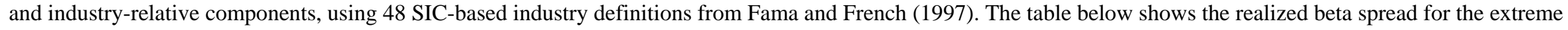

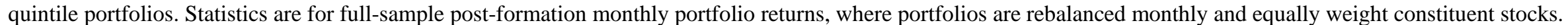

\begin{tabular}{|c|c|c|c|c|c|c|}
\hline & \multicolumn{2}{|c|}{ EW High Beta Quintile } & \multicolumn{2}{|c|}{ EW Low Beta Quintile } & \multicolumn{2}{|c|}{ Difference } \\
\hline & Beta & T-stat & Beta & T-stat & Spread & T-stat \\
\hline 5 Year, Monthly Beta & 1.51 & {$[28.56]$} & 0.65 & {$[18.43]$} & -0.86 & {$[-19.56]$} \\
\hline 5 Year, Overlapping 3-Day Beta & 1.59 & {$[32.53]$} & 0.55 & {$[14.36]$} & -1.03 & {$[-21.56]$} \\
\hline $\begin{array}{l}5 \text { Year, Overlapping 3-Day Correlation } \\
\text { with } 1 \text { Year Daily Volatility }\end{array}$ & 1.59 & {$[27.89]$} & 0.55 & {$[14.41]$} & -1.05 & {$[-19.27]$} \\
\hline Industry Component & 1.40 & {$[29.44]$} & 0.73 & {$[21.66]$} & -0.66 & {$[-14.55]$} \\
\hline Within Industry Component & 1.52 & {$[28.48]$} & 0.70 & [18.38] & -0.82 & {$[-18.86]$} \\
\hline
\end{tabular}


Table III. Tilts and Trades, 1968-2014. We compute performance for seven strategies, annual autocorrelation of firm characteristic values, and the correlation of firm characteristic values with market capitalization. We examine the Fama-French factors, along with momentum, reversal, and beta. We label the first four, which are high autocorrelation strategies, as "Tilts.” We label the next three, which are low autocorrelation strategies with low correlation to market capitalization, as illiquid "Trades.” In the first set of three columns, we compute the raw return, standard deviation, and Sharpe ratio of simple Fama-French factor portfolios. Fama-French factor portfolios divide the CRSP sample into six, value-weighted portfolios by characteristic $(30,40,30)$ and size (above median, below median) and compute the corresponding factor return as the average of the two high characteristic portfolios minus the average of the two low characteristic portfolios. We compute the beta portfolio using 5-year, overlapping 3-day autocorrelations and 1-year daily volatility as in Table I. The remaining portfolios are drawn directly from Ken French's data library. In the second set of four columns, we remove the in-sample beta risk from each portfolio, reporting the beta, alpha, standard deviation, and the Sharpe ratio of the alpha portfolio. In the last set of three columns, we use the definitions in Table I and from Ken French's data library to compute the annual autocorrelation of firm characteristics and the correlation of above-median characteristics and (the opposite of) below-median characteristic with market capitalization from CRSP. Statistics are for full-sample, postformation monthly portfolio returns, where portfolios are rebalanced annually at the end of each June except for Momentum and Reversal which are rebalanced monthly.

\begin{tabular}{|c|c|c|c|c|c|c|c|c|c|c|c|}
\hline & \multicolumn{3}{|c|}{$\begin{array}{c}\text { Simple Strategy Performance, } \\
\text { Annualized }\end{array}$} & \multicolumn{4}{|c|}{$\begin{array}{c}\text { Market-Neutral Strategy Performance, } \\
\text { Annualized }\end{array}$} & \multicolumn{4}{|c|}{ Characteristic Correlation } \\
\hline & Return & SD & Sharpe & Beta & Alpha & $\begin{array}{r}\text { SD } \\
\text { (Alpha) }\end{array}$ & $\begin{array}{l}\text { Sharpe } \\
\text { (Alpha) }\end{array}$ & $\begin{array}{r}1-Y e a r \\
\text { Lag }\end{array}$ & $\begin{array}{c}\text { Market } \\
\text { Cap + }\end{array}$ & $\begin{array}{r}\text { Market } \\
\text { Cap - }\end{array}$ & $\begin{array}{l}\text { Low } \\
\text { Beta }\end{array}$ \\
\hline Low Beta & 1.82 & 16.18 & 0.11 & -0.78 & 6.43 & 10.33 & 0.62 & 0.88 & -0.30 & -0.01 & 1.00 \\
\hline Value & 4.51 & 10.21 & 0.44 & -0.20 & 5.70 & 9.68 & 0.59 & 0.81 & -0.30 & -0.04 & 0.15 \\
\hline Small Size & 2.41 & 10.71 & 0.22 & 0.19 & 1.31 & 10.29 & 0.13 & 0.97 & -1.00 & 1.00 & 0.26 \\
\hline High Profits & 3.19 & 7.62 & 0.42 & -0.10 & 3.79 & 7.45 & 0.51 & 0.72 & -0.01 & -0.34 & -0.01 \\
\hline Low Growth & 4.48 & 6.93 & 0.65 & -0.18 & 5.52 & 6.34 & 0.87 & 0.30 & -0.33 & -0.05 & 0.02 \\
\hline Momentum & 7.89 & 15.04 & 0.52 & -0.13 & 8.64 & 14.91 & 0.58 & 0.05 & -0.31 & -0.06 & -0.08 \\
\hline Reversal & 5.86 & 11.21 & 0.52 & 0.21 & 4.65 & 10.72 & 0.43 & 0.03 & -0.12 & -0.21 & 0.02 \\
\hline
\end{tabular}


Table IV. Fama French Factors: Small versus Large, Long versus Short, 1968-2014. We examine the performance of various portfolio construction methods for a value portfolio. The standard HML from Fama-French takes the average across small and big stocks of the difference in return of the top $30 \%$ of value scores and the bottom $30 \%$ of value scores. Small is defined as below the $50^{\text {th }}$ percentile in the NYSE by market capitalization. Value also is defined using NYSE breakpoints. We consider variants on this which use only small stocks, only big stocks, and only the top $30 \%$ less a risk-free rate, rather than the long-short implementation. Portfolios are rebalanced annually at the end of each June.

\begin{tabular}{|c|c|c|c|c|c|c|}
\hline & \multicolumn{4}{|c|}{$H M L$} & \multicolumn{2}{|c|}{$\begin{array}{l}\text { Small HML on Big } \\
H M L, \text { Big on Small }\end{array}$} \\
\hline & $\begin{array}{r}\text { HML, } \\
\text { Small } \\
\text { Stocks }\end{array}$ & $\begin{array}{r}\text { HML, Big } \\
\text { Stocks } \\
\end{array}$ & $\begin{array}{r}\text { Long } \\
\text { Value, } \\
\text { Small } \\
\text { Stocks }\end{array}$ & $\begin{array}{r}\text { Long } \\
\text { Value, } \\
\text { Big } \\
\text { Stocks } \\
\end{array}$ & $\begin{array}{r}\text { HML, } \\
\text { Small } \\
\text { Stocks }\end{array}$ & $\begin{array}{r}\text { HML, Big } \\
\text { Stocks } \\
\end{array}$ \\
\hline Annualized Alpha (\%) & $\begin{array}{r}0.22 \\
{[4.03]}\end{array}$ & $\begin{array}{r}-0.22 \\
{[-4.02]}\end{array}$ & $\begin{array}{r}0.18 \\
{[1.63]}\end{array}$ & $\begin{array}{r}-0.12 \\
{[-2.87]}\end{array}$ & $\begin{array}{r}0.52 \\
{[5.30]}\end{array}$ & $\begin{array}{r}-0.20 \\
{[-2.00]}\end{array}$ \\
\hline Market & $\begin{array}{r}-0.10 \\
{[-7.70]}\end{array}$ & $\begin{array}{r}0.10 \\
{[7.70]}\end{array}$ & $\begin{array}{r}1.15 \\
{[45.61]}\end{array}$ & $\begin{array}{r}1.05 \\
{[108.74]}\end{array}$ & $\begin{array}{r}-0.23 \\
{[-10.57]}\end{array}$ & $\begin{array}{r}0.09 \\
{[3.60]}\end{array}$ \\
\hline HML & $\begin{array}{r}0.99 \\
{[50.66]}\end{array}$ & $\begin{array}{r}1.01 \\
{[51.83]}\end{array}$ & $\begin{array}{r}0.55 \\
{[14.05]}\end{array}$ & $\begin{array}{r}0.74 \\
{[49.06]}\end{array}$ & & \\
\hline HML, Small Stocks & & & & & & $\begin{array}{r}0.65 \\
{[20.04]}\end{array}$ \\
\hline HML, Big Stocks & & & & & $\begin{array}{r}0.63 \\
{[20.04]}\end{array}$ & \\
\hline $\mathbf{N}$ & 1,073 & 1,073 & 1,073 & 1,073 & 1,066 & 1,066 \\
\hline R-Squared & 0.85 & 0.83 & 0.78 & 0.95 & 0.51 & 0.43 \\
\hline
\end{tabular}


Table V. Shared Risk in Beta Tilts, 1968-2014. We decompose the variance of a long-short beta portfolio into components shared by: value, size, and profit tilts; growth, momentum, and reversal trades; and bond market measures of duration and credit. Each strategy is orthogonalized to the overall equity market. The remaining variance is unique to a beta tilt. Statistics are for full-sample, post-formation monthly portfolio returns, where portfolios are rebalanced annually at the end of each June except for Momentum and Reversal which are rebalanced monthly.

\begin{tabular}{|c|c|c|c|c|c|c|c|c|c|c|c|}
\hline & \multicolumn{9}{|c|}{ Market-Neutral Covariances } & \multirow[b]{2}{*}{ Over-lap } & \multirow[b]{2}{*}{ Unique } \\
\hline & Value & $\begin{array}{c}\text { Small } \\
\text { Size }\end{array}$ & $\begin{array}{l}\text { High } \\
\text { Profits }\end{array}$ & $\begin{array}{c}\text { Low } \\
\text { Growth }\end{array}$ & Mom & Re-versal & Duration & Credit & $\begin{array}{c}\text { Multi } \\
\text { Variate }\end{array}$ & & \\
\hline \multirow[t]{2}{*}{ Value } & 0.31 & & & & & & & & 0.20 & & \\
\hline & {$[4.25]$} & & & & & & & & [2.30] & & \\
\hline Small Size & & -0.41 & & & & & & & -0.29 & & \\
\hline High Profits & & & [6.17] & & & & & & [5.39] & & \\
\hline \multirow[t]{2}{*}{ Low Growth } & & & & 0.38 & & & & & 0.27 & & \\
\hline & & & & {$[4.25]$} & & & & & {$[2.86]$} & & \\
\hline \multirow[t]{2}{*}{ Momentum } & & & & & 0.13 & & & & 0.15 & & \\
\hline & & & & & {$[2.14]$} & & & & [3.55] & & \\
\hline \multirow[t]{2}{*}{ Credit } & & & & & & & & -0.22 & 0.17 & & \\
\hline & & & & & & & & {$[-1.82]$} & [1.65] & & \\
\hline Variance Explained & 9.10 & 18.09 & 12.96 & 5.95 & 3.99 & 0.56 & 10.58 & 1.31 & 43.50 & -19.04 & 63.30 \\
\hline Percent Variance Explained (\%) & 8.52 & 16.94 & 12.13 & 5.57 & 3.74 & 0.52 & 9.91 & 1.22 & 40.73 & -17.83 & 59.27 \\
\hline
\end{tabular}


Table VI. Sources of Return in Beta, 1968-2014. We decompose the return on a long-short beta portfolio into components shared by: value, size, and profit tilts; and

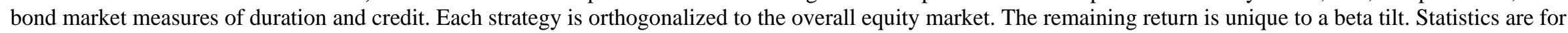
full-sample, post-formation monthly portfolio returns, where portfolios are rebalanced annually at the end of each June.

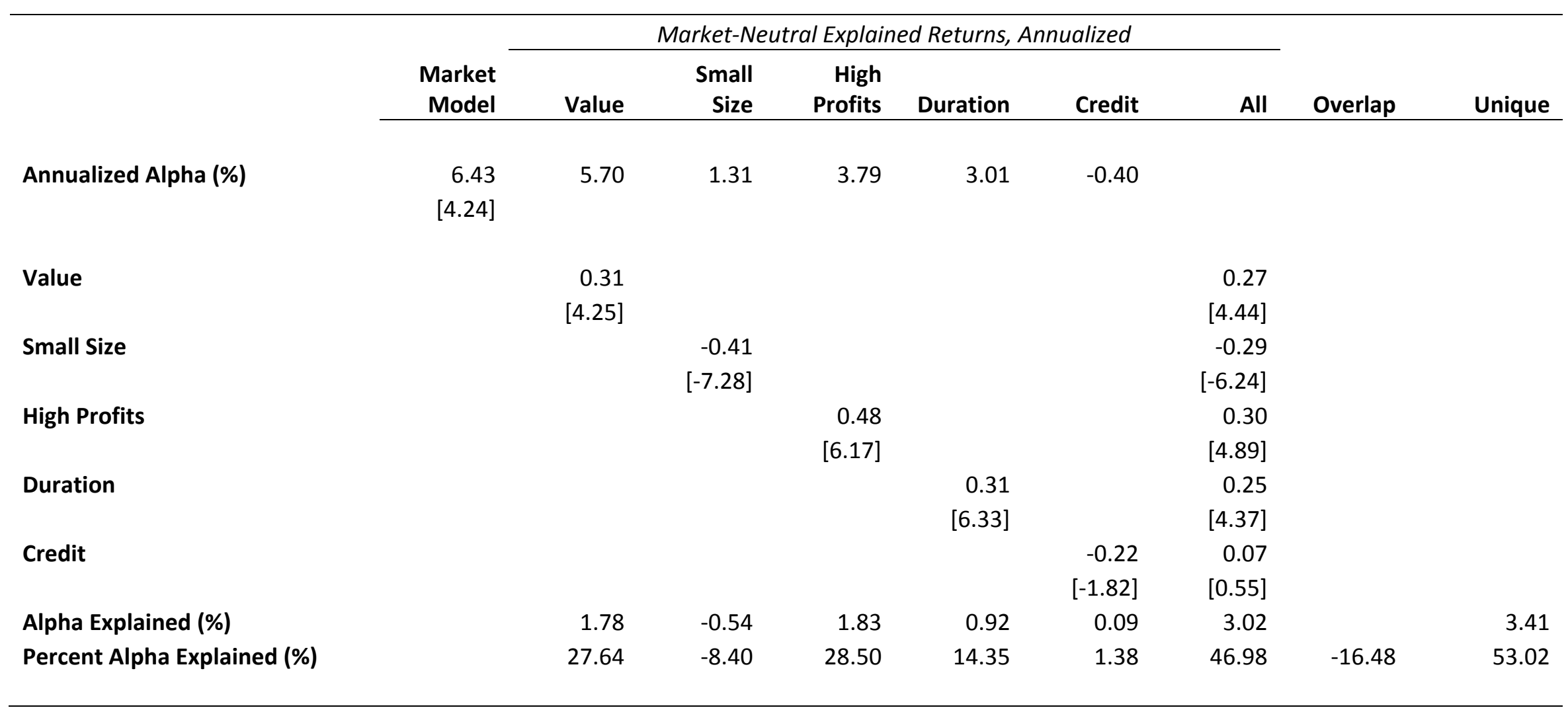




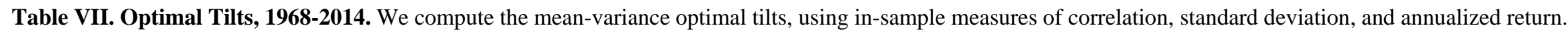

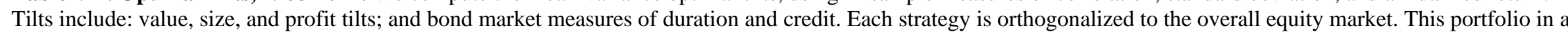

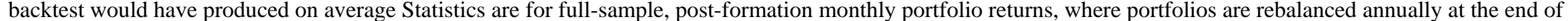
each June.

\begin{tabular}{|c|c|c|c|c|c|c|c|c|c|c|}
\hline & \multirow[b]{2}{*}{$\begin{array}{r}\text { Optimal } \\
\text { Tilt }\end{array}$} & \multicolumn{3}{|c|}{$\begin{array}{l}\text { Market-Neutral Strategy } \\
\text { Performance, Annualized }\end{array}$} & \multicolumn{6}{|c|}{ In Sample Correlations } \\
\hline & & Raw (\%) & $\begin{array}{r}\text { Per SD } \\
(\%)\end{array}$ & Sharpe & Beta & Value & $\begin{array}{r}\text { Small } \\
\text { Size }\end{array}$ & $\begin{array}{l}\text { High } \\
\text { Profits }\end{array}$ & $\begin{array}{r}\text { Duratio } \\
\mathbf{n}\end{array}$ & Credit \\
\hline Low Beta & $24 \%$ & 6.43 & 2.16 & 0.62 & 1.00 & & & & & \\
\hline Value & $20 \%$ & 5.70 & 2.04 & 0.59 & 0.29 & 1.00 & & & & \\
\hline Small Size & $26 \%$ & 1.31 & 0.44 & 0.13 & -0.41 & -0.04 & 1.00 & & & \\
\hline High Profits & $23 \%$ & 3.79 & 1.76 & 0.51 & 0.35 & 0.04 & -0.34 & 1.00 & & \\
\hline Duration & $7 \%$ & 3.01 & 0.98 & 0.28 & 0.31 & 0.05 & -0.16 & 0.10 & 1.00 & \\
\hline Credit & $0 \%$ & -0.40 & -0.27 & -0.08 & -0.11 & 0.11 & 0.09 & -0.11 & -0.49 & 1.00 \\
\hline Portfolio (Annual) & & & 3.33 & 0.96 & & & & & & \\
\hline
\end{tabular}

